\title{
Rotating biological contactors: a review on main factors affecting performance
}

\author{
S. Cortez $\cdot$ P. Teixeira $\cdot$ R. Oliveira $\cdot$ M. Mota
}

Published online: 24 January 2008

(C) Springer Science+Business Media B.V. 2008

\begin{abstract}
Rotating biological contactors (RBCs) constitute a very unique and superior alternative for biodegradable matter and nitrogen removal on account of their feasibility, simplicity of design and operation, short start-up, low land area requirement, low energy consumption, low operating and maintenance cost and treatment efficiency. The present review of RBCs focus on parameters that affect performance like rotational speed, organic and hydraulic loading rates, retention time, biofilm support media, staging, temperature, influent wastewater characteristics, biofilm characteristics, dissolved oxygen levels, effluent and solids recirculation, stepfeeding and medium submergence. Some RBCs scale-up and design considerations, operational problems and comparison with other wastewater treatment systems are also reported.
\end{abstract}

Keywords Aerobic/Anaerobic/Anoxic RBC . Design $\cdot$ Medium submergence $\cdot$ Rotational speed . Scale-up $\cdot$ Staging

S. Cortez $(\bowtie) \cdot$ P. Teixeira $\cdot$ R. Oliveira $\cdot$ M. Mota IBB - Institute for Biotechnology and Bioengineering, Centre of Biological Engineering, University of Minho, Campus de Gualtar, 4710-057 Braga, Portugal

e-mail: susana_cortez@deb.uminho.pt

\section{Introduction}

A rotating biological contactor (RBC) is an attached growth bioreactor that offers an alternative technology to the conventional activated sludge process.

The first RBC system was used in the early 1900s and consisted of a cylinder with wooden slats (Mathure and Patwardhan 2005). The availability of polystyrene marked the beginning of commercial application of RBCs with the first full-scale system being installed in Germany in 1958 (Rodgers and Zhan 2003). Significant refinements in media type and equipment configuration occurred during the 1960s and early 1970s (Tchobanoglous and Burton 1991; Grady et al. 1999). Currently, there are many thousands of units operating worldwide and several different designs available depending upon specific requirement criteria (Mba et al. 1999).

A RBC unit typically consists of a series of closely spaced large flat or corrugated discs that are mounted on a common horizontal shaft and are partially or completely submerged in wastewater (Fig. 1). A drum filled with some lightweight packed supports can also be used in place of conventional discs. The shaft continually rotates by a mechanical motor or a compressed air drive and a biofilm is established onto the entire surface area of the media, which metabolizes the organic materials contained in the wastewater. In aerobic processes the rotation of the media promotes oxygen transfer and maintains the biomass in aerobic conditions. The rotation also 

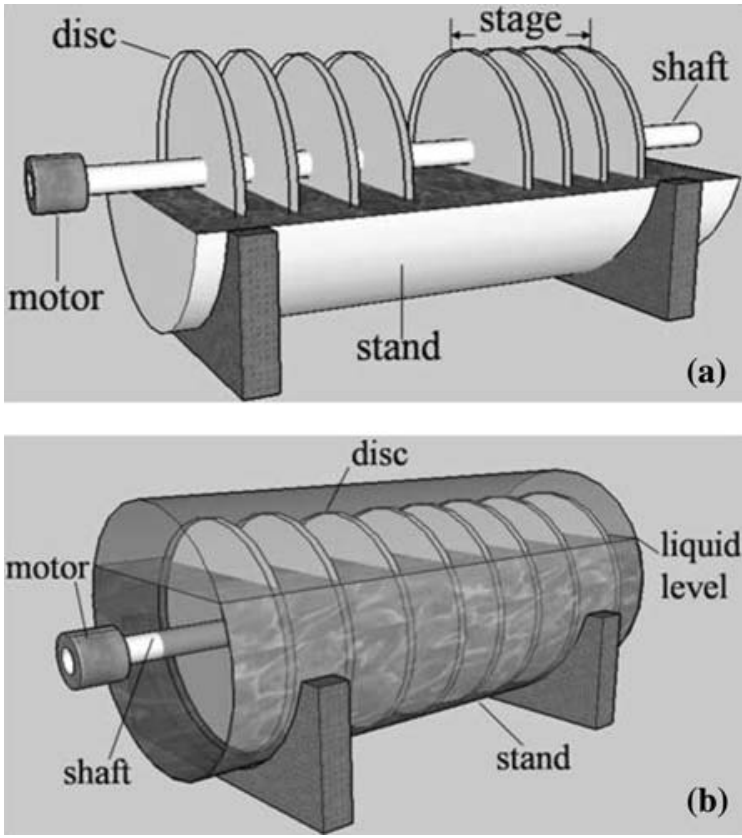

Fig. 1 Schematic diagram of RBC units: (a) conventional RBC with two-stages; (b) single-stage closed RBC with high submergence level

provides turbulence in the mixed liquor surface and enables the removal of excess solids from the media (Patwardhan 2003; Rodgers and Zhan 2003). Biomass clarification is used to remove these solids.

RBC systems due to their advantages (Table 1) constitute a very unique and superior alternative for biodegradable matter and nitrogen removal.
Over the years RBCs have been successfully used to provide secondary treatment to municipal wastewater from small units serving residential dwellings to large ones treating flows of up to several million litres per day (Banerjee 1997a). They have also been used to nitrify municipal wastewater, either in combined carbon oxidation and nitrification applications or in separate stage nitrification applications, denitrification and phosphorus removal. In addition, decolourization of wastes like textile dyes (Axelsson et al. 2006) and coloured sugar refinery effluents (Guimarães et al. 2005); bioremediation of landfill leachates (Cema et al. 2007) or organopollutants such as of chlorophenols (Majumder and Gupta 2007, Radwan and Ramanujam 1997) and trichloroethylene (Brar and Gupta 2000); treatment of effluents from wineries (Malandra et al. 2003), bakeries (Nahid et al. 2001), food processors (Nasr et al. 2006), pulp and paper mills (Selvam et al. 2002), leather tanneries (Zao-yan and Zhen-san 1990) and other biodegradable industrial discharges can be performed by the RBC system.

In the last decade, RBC facilities tightly closed to avoid air entrance started to be used for anoxic (denitrification) (Teixeira and Oliveira 2001) or anaerobic processes ( $\mathrm{Lu}$ and Yeh 1995; $\mathrm{Lu}$ et al. 1997a, b).

The RBC system optimisation and adaptability under different environmental conditions and influent characteristics remain challenging tasks for the efficient design and use of this technology.
Table 1 General advantages and drawbacks of the RBC process

\begin{tabular}{ll}
\hline Advantages & Drawbacks \\
\hline $\begin{array}{l}\text { Land requirement relatively small } \\
\text { Easy construction and expansion }\end{array}$ & $\begin{array}{l}\text { Difficult scale-up } \\
\text { Slow process start-up } \\
\text { Compact design with separate compartments }\end{array}$ \\
$\begin{array}{l}\text { Adequate primary treatment } \\
\text { and secondary clarifier required }\end{array}$ \\
$\begin{array}{l}\text { Low operating and maintenance cost } \\
\text { Short HRTs }\end{array}$ \\
High OTE \\
High biomass concentration per volume \\
reactor \\
Low sludge volume index values \\
in the second clarifier \\
No requirement of sludge recirculation \\
Resistance to shock and toxic loads \\
No problems with malodours and flies
\end{tabular}




\section{Factors affecting performance}

The performance of RBCs depends upon several design parameters. Particularly significant are: rotational speed, organic and hydraulic loading rates, hydraulic retention time (HRT), RBC media, staging, temperature, wastewater and biofilm characteristics, dissolved oxygen (DO) levels, effluent and solids recirculation, step-feeding and medium submergence.

\subsection{Rotational speed}

The rotational speed of the RBC media is a very important parameter that affects nutrient and oxygen mass transfer in the biofilm and consequently substrate removal. Table 2 summarizes some studies on the effect of rotational speed in the performance of RBC systems.

Usually an increase on the speed of rotation increases the dissolved oxygen concentration available to the microorganisms and as a result they are able to degrade the substrate at a higher rate (Israni et al. 2002). However, increasing the rotational speed leads to higher power consumption, which may not be economical for wastewater treatment applications (Ramsay et al. 2006). Besides, if the rotational speed gets too high, the microorganisms will be stripped off the media, deteriorating the effluent quality and lowering the biodegradation rate in the reactor.

Packed supports will provide considerably more oxygenation than disc RBCs at the same rotational speed, but they will require greater power consumption (Hoccheimer and Wheaton 1998).

Thus, the guiding principle is to adopt the minimum speed commensurate with acceptable treatment. According to Mathure and Patwardhan (2005), typically rotational speeds are $1-10 \mathrm{rpm}$ for $\mathrm{RBC}$ media in disc form with discs with 1-4 $\mathrm{m}$ diameter mounted on shafts around 5-10 m long.

\subsection{Organic loading}

The organic loading of a $\mathrm{RBC}$ reactor must be accurately defined during planning and designing. The variation of the organic loading rate is generally accomplished by changing the inlet flow rate or the HRT, which also results in a change in the hydraulic loading (Najafpour et al. 2005). Table 3 summarizes the experimental details and performance results of different works to study the effect of organic loading on the performance of some RBC systems.

Available data show that, for a given system, as the applied organic loading rate increases, the substrate removal rate increases and removal efficiency decreases. Reduction in substrate removal efficiency may be an indication of limitation in dissolved oxygen.

Under normal operating conditions, carbonaceous substrate is mainly removed in the first-stage of the RBC. To avoid oxygen transfer limitations the firststage design load must be limited to a $\mathrm{BOD}_{5}$ load of about $30 \mathrm{~g} \mathrm{BOD}_{5} / \mathrm{m}^{2} \mathrm{~d}$ or to a soluble $\mathrm{BOD}_{5}$ load of 12-20 $\mathrm{g} \mathrm{BOD}_{5} / \mathrm{m}^{2} \mathrm{~d}$ according to WEF and ASCE (WEF and ASCE 1998). The use of higher first-stage organic loadings will increase the probability of developing problems such as excessive biofilm thickness, depletion of dissolved oxygen, deterioration of process performance, appearance of $\mathrm{H}_{2} \mathrm{~S}$ odours and excessive growth of nuisance organisms such as Beggiatoa (Tchobanoglous and Burton 1991; Grady et al. 1999). Overloading problems can be overcome by removing baffles between the first and second-stages to reduce surface loading and increase oxygen transfer. Other approaches include supplemental air systems, step-feed, or recycle from the last stage (Surampalli and Bauman 1997).

The organic loading affects nitrification in a RBC unit. In the initial stages, where the organic load is high, heterotrophic bacteria offer strong competition to nitrifiers displacing them within the bioreactor (Brazil 2006). Therefore, the maximum nitrification rate occurs when the soluble BOD load reduces sufficiently, which always takes place in the latter stages of the RBC set-up. In the case of full-scale RBCs for nitrification of municipal wastewater with four units in series, the German ATV guideline (ATV 1989) proposes a design value of $5 \mathrm{~g} \mathrm{BOD} / \mathrm{m}^{2} \mathrm{~d}$. Nowak (2000) has investigated nitrification in full-scale RBCs (with discs and plastic packages) and proposed that the surface loading rate should not exceed $2.5 \mathrm{~g} \mathrm{BOD}_{5} / \mathrm{m}^{2} \mathrm{~d}$ to keep the effluent ammonia concentration below $5 \mathrm{mg} \mathrm{NH}_{4}^{+}-\mathrm{N} / \mathrm{l}$, at temperatures above $13^{\circ} \mathrm{C}$. In the same investigation nitrification rates of $1.5 \mathrm{~g} \mathrm{~N}$ oxidized $/ \mathrm{m}^{2} \mathrm{~d}$ at $8^{\circ} \mathrm{C}$ and of $1.8 \mathrm{~g} \mathrm{~N}$ oxidized $/ \mathrm{m}^{2} \mathrm{~d}$ at $13^{\circ} \mathrm{C}$ were obtained in tertiary full-scale RBCs with ammonia effluent concentrations mostly below $4 \mathrm{mg} \mathrm{NH}+-\mathrm{N} / 1$. 


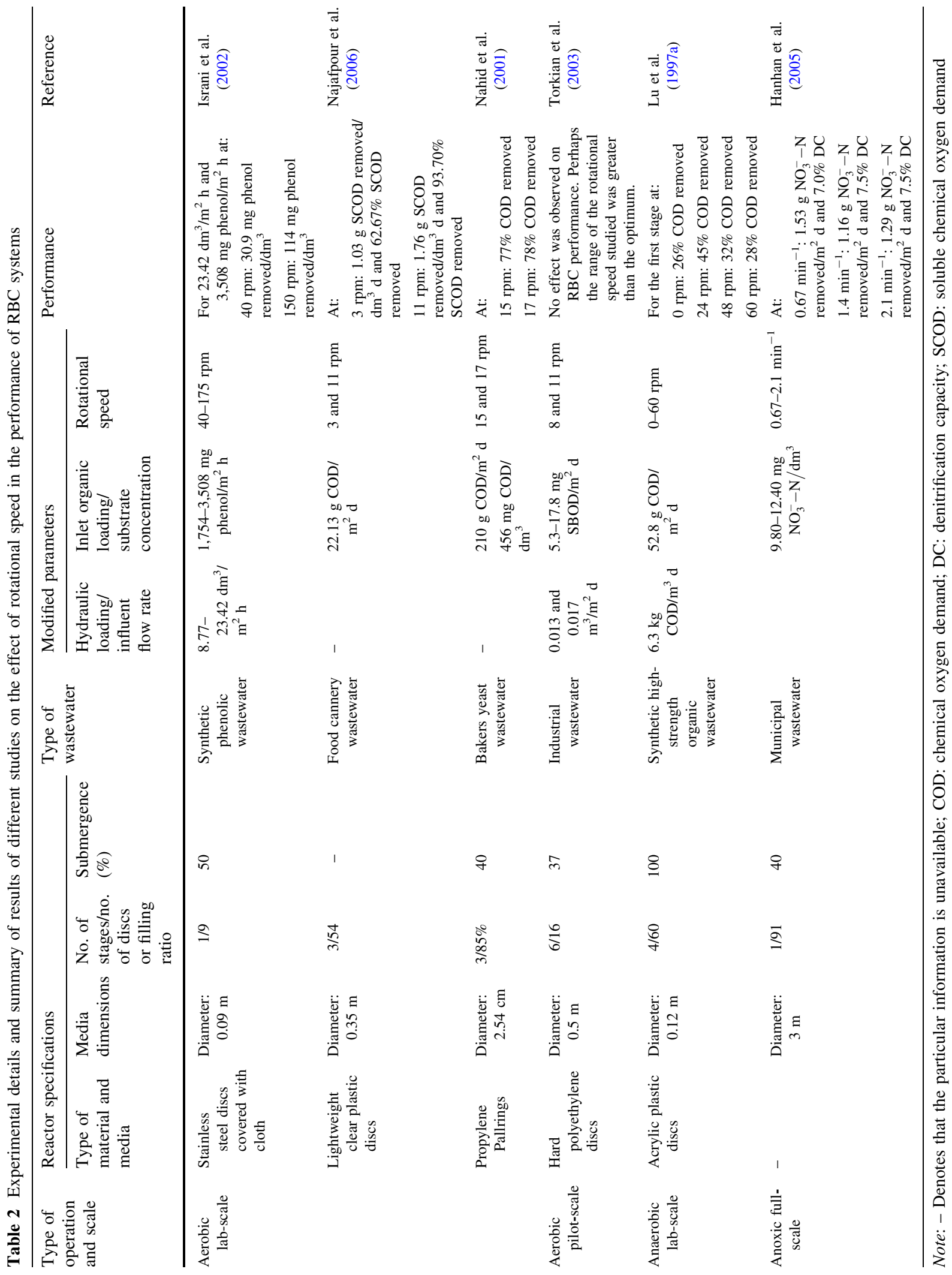




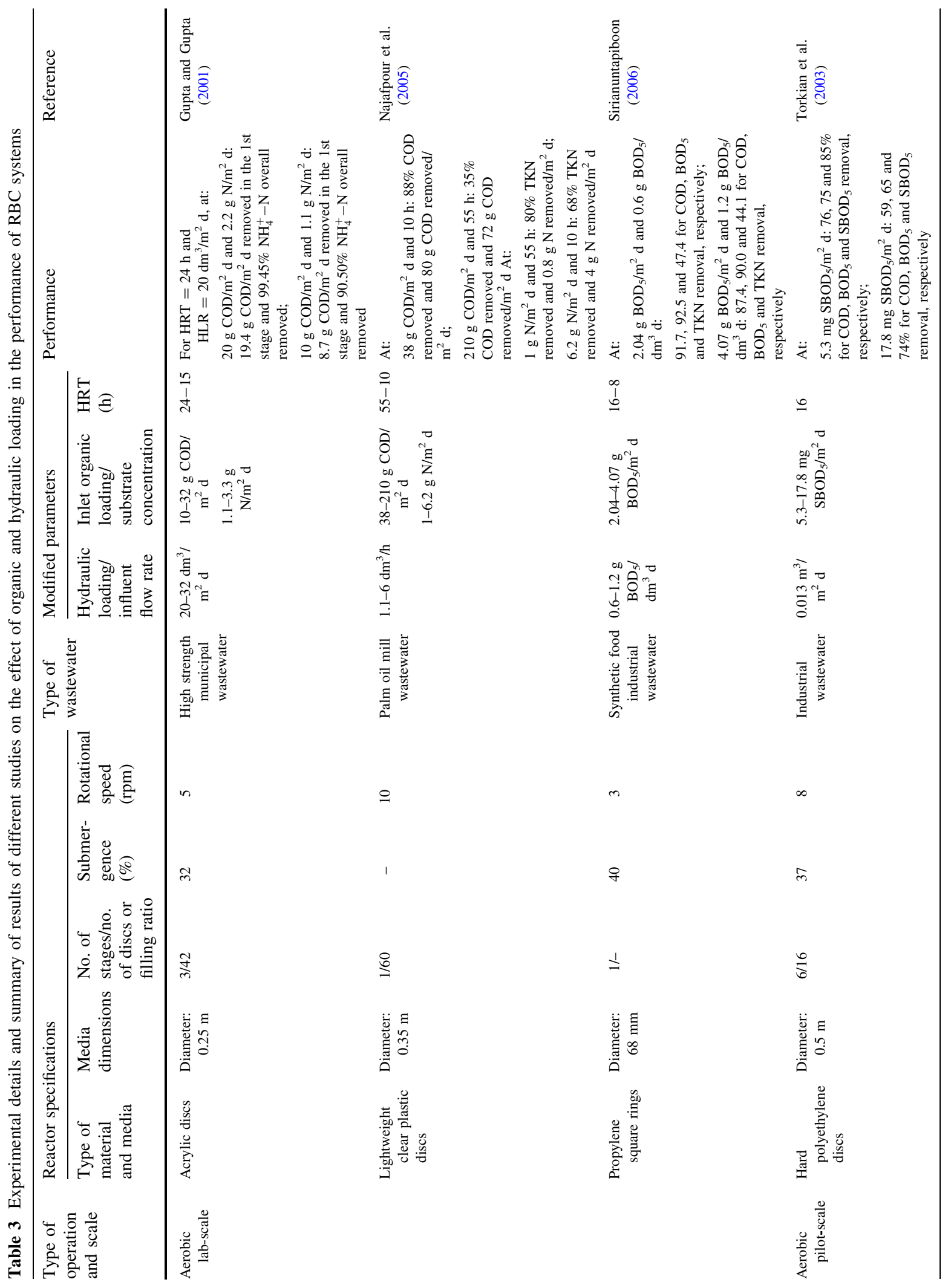




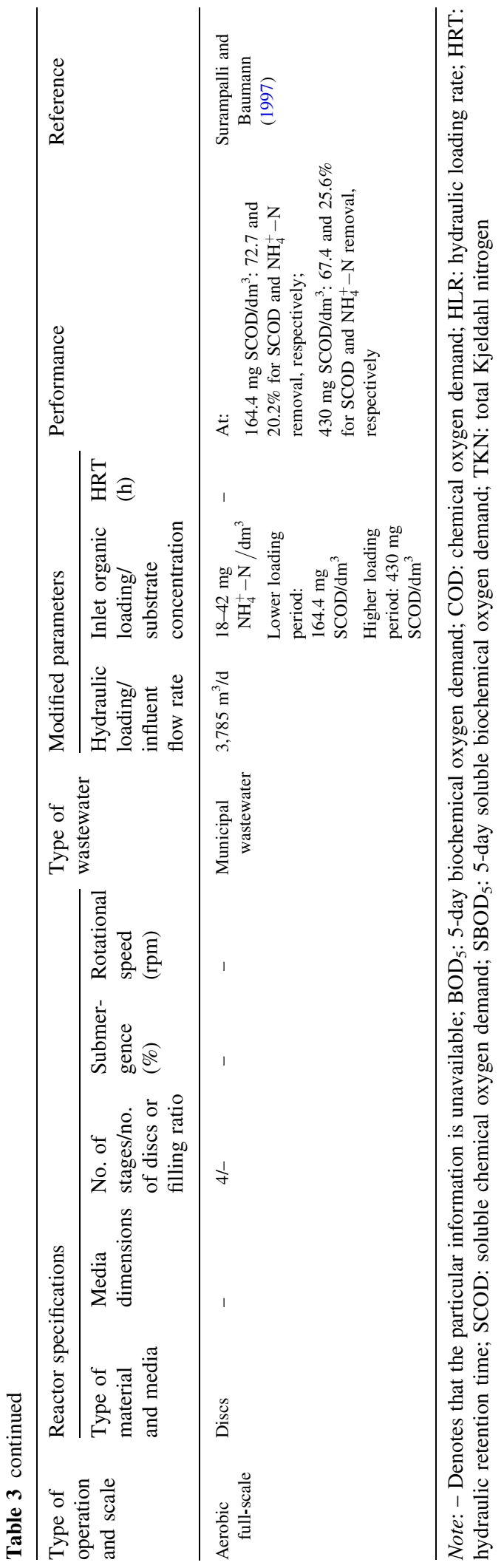

\subsection{Hydraulic loading}

The performance of RBCs has historically been correlated with hydraulic loading. Increasing the flow rate through the bioreactor reduces the liquid retention time in the system and results in a reduction in removal efficiency (Table 3 ). In defined conditions increasing hydraulic loading also leads to an increase of attached biomass on RBC media surface (Alemzadeh and Vossoughi 2001).

Hydraulic loading rates vary widely depending on the design, the substrate being removed and the effluent concentration desired (Hoccheimer and Wheaton 1998). Some RBC manufacturers developed design relationships for municipal wastewater in which effluent quality is plotted as a function of hydraulic loading, at a given temperature. These relationships are very useful for characterizing full-scale RBC facilities performance. However, since in these relationships the intrinsic biodegradation constants and hydrodynamics of the system are not taken into consideration and equipment manufacturers provide optimistic estimates, care should be exercised in the selection and application of such empirical relationships (Grady et al. 1999). Typical hydraulic loading rate range recommended by RBC manufacturers (full-scale) is $1.292-6.833 \mathrm{dm}^{3} / \mathrm{m}^{2} \mathrm{~h}$ (Tchobanoglous and Burton 1991).

Due to the large amount of biological mass present (low operating feed/microorganisms) RBCs offer good stability under high or toxic hydraulic and organic loadings (Sirianuntapiboon 2006).

\subsection{Hydraulic retention time}

Studies with RBC systems have revealed that longer contact times improve the diffusion of the substrate into the biofilm and its consequent removal of the influent (Hanhan et al. 2005; Najafpour et al. 2006). This trend is also verified with toxic and heavy metals substrates (Costley and Wallis 2000; Majumder and Gupta 2007; Sirianuntapiboon and Chuamkaew 2007).

Too short a HRT will result in low removal rates, whereas too long a HRT will not be economically feasible. In order for a biological system to compete successfully with conventional physicochemical methods of treatment, the shortest possible HRT 
associated with the most efficient removal rates is required (Costley and Wallis 2000).

A significant advantage offered by full-scale RBCs is to require short hydraulic retention periods (generally less than $1 \mathrm{~h}$ ) (Benefield and Randall 1980).

\subsection{RBC media}

RBC systems have evolved considerably from the original design of several rotating discs. Many variations now exist, ranging from simple flat discs through corrugations to cellular meshes all of which are designed to give extra surface area per unit volume (Fig. 2). However, as the supporting medium gets more complex its cost increases (Ware et al. 1990).

The media used for RBCs are actually produced from Styrofoam, polycarbonate sheets or high-density polyethylene (HDPE) and others (Tables 2, 3). HDPE containing UV inhibitors such as carbon black is the material most commonly used and is provided in different configurations or corrugation patterns (Ware et al. 1990; Rodgers and Zhan 2003). Corrugations enhance structural stability, improve mass transfer and increase the available surface area (Grady et al. 1999). The types of biofilm supporting media are classified on the basis of surface area provided and are commonly termed low- (or standard-) density, medium-density and high-density. Standard-density media are defined as having a surface area of about $115 \mathrm{~m}^{2} / \mathrm{m}^{3}$ of reactor, with larger spaces between media layers and are normally used in the lead stages of a RBC process train. Medium and high-density media have surface areas of about $135-200 \mathrm{~m}^{2} / \mathrm{m}^{3}$ of reactor and are used typically in the middle and final stages of a RBC system where thinner biological growth occurs (Tchobanoglous and Burton 1991; Patwardhan 2003). Standard-density media must be used in the first two stages that are highly loaded or where Beggiatoa growth is possible because excess biological growths are more difficult to remove from high-density media (Grady et al. 1999).

Some modifications of conventional RBCs media have been explored at laboratory-scale with positive results concerning substrate removal. In order to enhance biofilm area and volume, Radwan and Ramanujam (1997) modified RBC discs by attaching porous netlon sheets. Guimarães et al. (2005) also
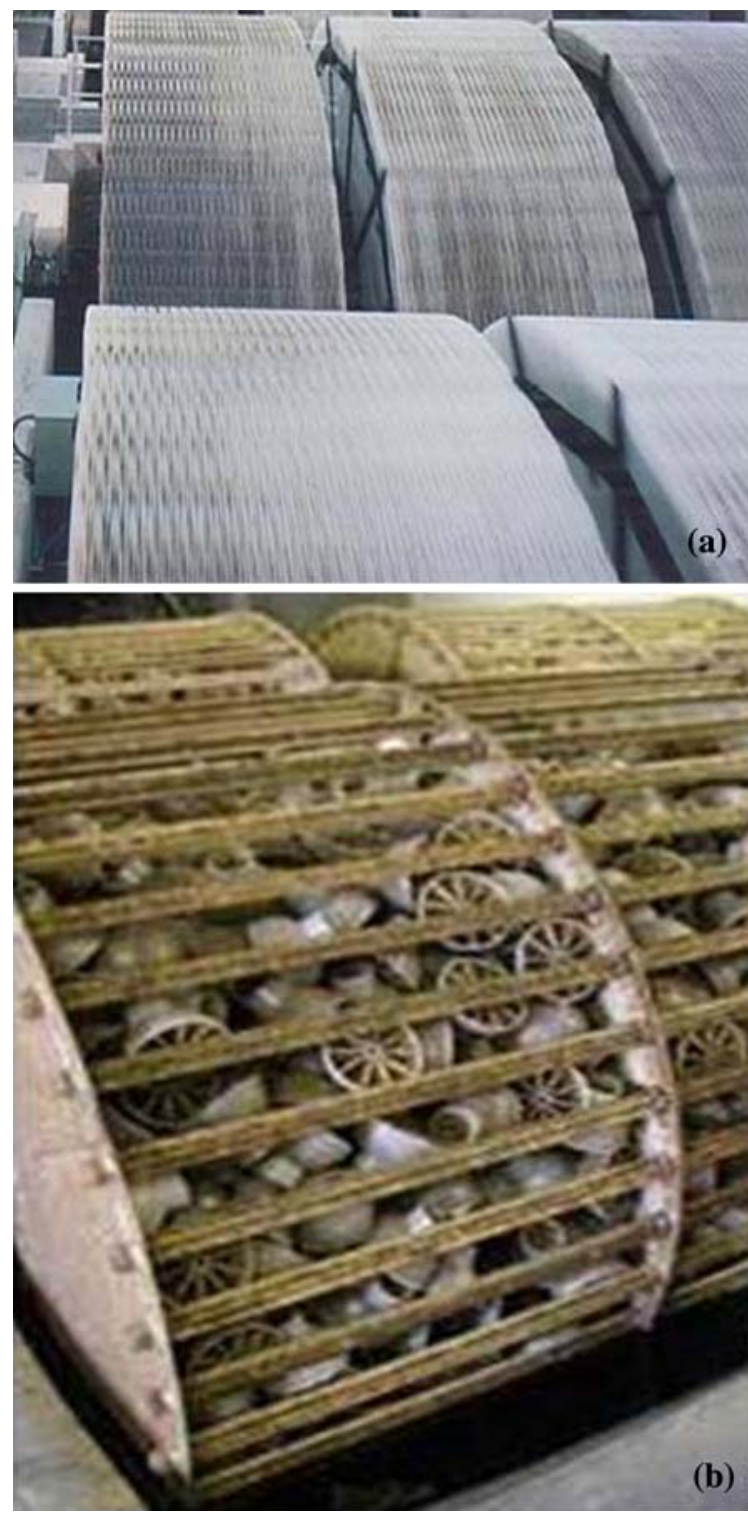

Fig. 2 (a) Closely spaced discs in a full-scale RBC (http:// www.dmw.co.jp); (b) RBC with a random packed medium (http://www.wateronline.com)

attached a layer of polyurethane foam on plastic discs in order to enhance the adhesion of filamentous organisms.

At the laboratory and pilot-scale, random packed media have been successfully used as substitutes for discs. Such media provide more area for attachment of the biofilm within the same RBC reactor size, contributing to higher mass transfer efficiency due to increased turbulence. Besides they have low energy consumption and the fabrication cost is nearly one 
third that of discs (Ware et al. 1990; Mathure and Patwardhan 2005). Different types of packing such as Pallrings, saddles and cylindrical plastic elements with distinctive sizes have been applied in random packed RBC systems presenting attractive results (Nahid et al. 2001; Mathure and Patwardhan 2005; Sirianuntapiboon 2006).

Whilst the use of random packed media is not new, few manufacturers are commercially exploiting it. On large-scale, like with conventional discs, some operational problems can occur, leading to a lot or any biofilm growth. With careful design it may be possible to develop packing media with the appropriate orientation and movement allowing the development of a suitable biofilm in a full-scale packed cage (Ware et al. 1990).

As recommendation, at the design stage of a particular RBC system, it is necessary to evaluate the characteristics of the wastewater being treated, the treatment objectives and to compare the various types of biofilm supporting media reported in the literature in terms of costs, the interfacial area offered, mass transfer coefficients, and power consumption. This will enable the process design engineer to choose the most appropriate type of medium (Patwardhan 2003).

\subsection{Staging}

Staging of $\mathrm{RBC}$ media is recommended to maximize removal of $\mathrm{BOD}_{5}$ and ammonia nitrogen $\left(\mathrm{NH}_{4}^{+}-\mathrm{N}\right)$. Stages are accomplished by using baffles in a tank or using a series of tanks. Typical RBC staging arrangements are illustrated in Fig. 3.

In secondary treatment applications, RBCs shall be designed and operated in a series of three stages per flow. For combined $\mathrm{BOD}_{5}$ and $\mathrm{NH}_{4}^{+}-\mathrm{N}$ removal a minimum of four stages is recommended per flow. For small plants, multiple stages are acceptable on a single shaft oriented in parallel to the direction of flow. In larger installations, shafts are mounted perpendicular to flow with several stages in series (Tchobanoglous and Burton 1991).

As the wastewater flows through the system, each subsequent stage receives an influent with an organic concentration lower than the previous stage. Because heterotrophic bacteria grow faster than nitrifiers the first stage tends to be primarily an organic removal device, unless the wastewater organic content is very
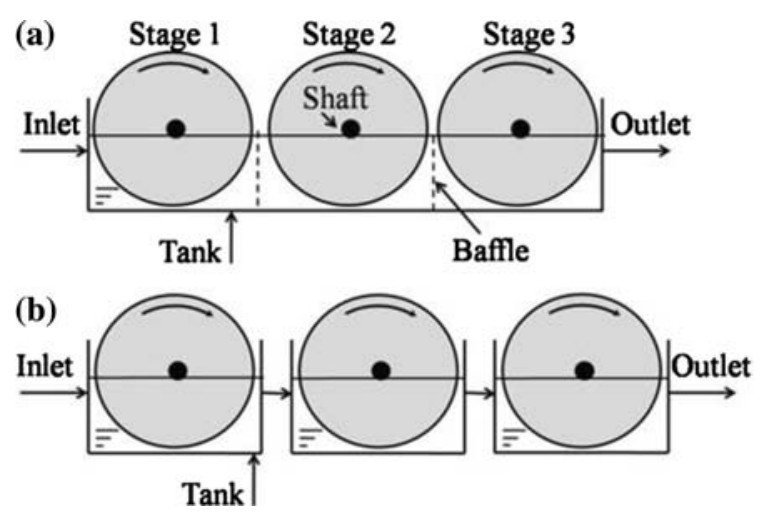

Fig. 3 Staging arrangements of RBC units accomplished by (a) baffles in a tank; (b) using a series of tanks, both with flow perpendicular to shaft

low. As the wastewater moves to the second and subsequent stages the RBC tends to first removing ammonia and then nitrite with the final product being nitrate, assuming that the RBC is sized and operated correctly (Hoccheimer and Wheaton 1998). When there is recycling of wastewater from the last stage to the first one, denitrification may be achieved in the first stage, where there is high organic loading and low dissolved oxygen content.

Experimental results of Banerjee (1997a) justify the use of staging in a $\mathrm{RBC}$ reactor, since mixing decreases gradually along the reactor, better approximating the system to the plug-flow regime. Radwan and Ramanujam (1997) concluded that staging in the design of RBC systems is especially important at higher organic loadings and also if high effluent treatment quality is required. Moreover, according to Tawfik et al. (2002) staging of RBC decreases the detrimental effect of shock load on the performance of the system.

Different numbers of stages have been used in several applications (Tables 2, 3). The number of stages to be used depends on the organic content of the influent, flow rate and several other variables (Hoccheimer and Wheaton 1998). Staging calculations, based on $\mathrm{COD}$ and $\mathrm{NH}_{4}^{+}-\mathrm{N}$ effluent concentrations, can be done using literature tables (Grady et al. 1999), with the appropriate adaptations.

\subsection{Temperature}

Temperature is one of the most important factors that affect the rate of biological processes and 
consequently influences $\mathrm{RBCs}$ performance. At limited conditions, an increase in the influent temperature leads to an increase in the microbial activity and a higher substrate removal can be observed in all RBC stages (Banerjee 1997b; Israni et al. 2002). Low influent temperatures can adversely affect biofilm establishment, particularly in its early stages (Costley and Wallis 2000). When wastewater temperatures less than $13^{\circ} \mathrm{C}$ are expected, organic and nitrogen removal rates may decrease.

Temperature correction factors need to be taken into account in design criteria and can be obtained from the equipment manufacturers or from pilot studies. Generally, when the temperature drops from 13 to $5^{\circ} \mathrm{C}$, nearly 2.5 times more media surface area is required for achieving the same performance (Rodgers and Zhan 2003).

In biofilms the nitrification process is less temperature-dependent than in activated sludge. The nitrification rate increases by about $4.5 \%$ per ${ }^{\circ} \mathrm{C}$ (Nowak 2000).

Year-round operation requires that rotating contactors be covered to protect the biological growth from freezing temperatures or excessive heat gain, which accelerates media deterioration. Covers also reduce heat loss, allow the offgas to be collected for odour control, and minimize algae growth. Individual covers are preferable than entire installations being placed in buildings (Tchobanoglous and Burton 1991).

\subsection{Wastewater characteristics}

The influent substances and its concentration levels may play a significant role in the operation of RBCs. For example, the flux into the biofilm may be smaller for large and slowly biodegradable compounds. The presence of particulate organic matter can reduce the flux of soluble substrate since the particulate matter occupies space within the biofilm, which decreases the rate of biodegradation (Grady et al. 1999).

When sulphide is present, either in the influent wastewater or by its production deep within the biofilm, sulphide-oxidizing bacteria such as Beggiatoa will grow on the biofilm surface. The production of sulphide within the biofilm is due to oxygen depletion. Beggiatoa will compete with heterotrophic organisms for oxygen and in extreme cases will take over the first-stage of an overloaded RBC, shifting the load to the next stage and progressively taking over the system (Mba et al. 1999).

RBC units properly designed and supplemented with essential nutrients consistently produce the best effluents and maintain biofilm on the media with better adhesion characteristics, especially when treating industrial wastewater.

\subsection{Biofilm characteristics}

To optimize the removal of organic matter and nitrogen compounds from wastewater in a RBC, an adequate understanding of the dynamic nature and characteristics of the biofilm, the major constituent of the process, is essential.

A biofilm is a living microbial system composed mainly of microorganisms, extracellular polymers, and water. The spatial distribution of these components within the biofilm matrix may influence the biofilm functions and the relationship to the immediate aquatic environment. This, in turn, depends on the operating conditions. For example, biofilm thickness depends on applied organic loading and shearing forces (Griffin and Findlay 2000).

Observations of full-scale RBCs biofilms treating municipal wastewaters report that biofilms from the initial stages have a gelatinous aspect, being usually greyish and may present some white zones probably due to filamentous bacteria like Beggiatoa. Biofilms of the last stages appear more compact: are always thinner than in the first stages and have a brown-like colour or sometimes reddish. In addition, the main limiting factor of microfauna growth is the degree of pollution in the influent expressed in terms of COD or $\mathrm{BOD}_{5}$. As long as this parameter decreases along the $\mathrm{RBC}$, its effect as a limiting factor decreases too, resulting in an increase in the majority of existing species. Initial stages are almost entirely constituted by species of ciliates, whereas the last stages show more diversified communities, not only in species of ciliates but also in flagellates, amoebae and metazoa (Martín-Cereceda et al. 2001a; Salvadó et al. 2004).

Microscopic studies reveal that the outer biofilm layer of a full-scale RBC is very heterogeneous and complex, mainly composed of filamentous bacteria, protozoa, green eukaryotic algae and small metazoans. The inner layer is more uniform and compact 
(Martín-Cereceda et al. 2001b). In aerobic RBC units for carbonaceous oxidation, during the initial stages, heterotrophs compete with nitrifiers in the outermost biofilm layer for oxygen and space. The microbial density is reduced in the innermost biofilm layer, which has a larger percentage of non-viable bacteria than the outer layer (Rodgers and Zhan 2003). The active metabolic cell fraction decreases from $35 \pm 13 \%$ in the outermost to $15 \pm 4 \%$ in the innermost biofilm (Okabe et al. 1996). When the depth of the biofilm is large and the concentration of dissolved oxygen in air is low, the outer layer acts aerobically and the inner side acts anoxic or anaerobically (Nahid et al. 2001). The filamentous organisms frequently present in the biofilm are Beggiatoa sp. and Sphaerotilus natans (Galvan et al. 2000). The development of Beggiatoa, as mentioned before, is always taken as a warning for the performance of RBC units because its blooming prevents the sloughing of thick biofilm from the discs, which can lead to overload on the media supports (Rodgers and Zhan 2003).

Biofilm ranging from 0.5 to $4.5 \mathrm{~mm}$ in thickness have been found in full-scale disc RBCs treating municipal wastewater. The biofilm thickness control is very important to avoid clogging or material fatigue stresses (Griffin and Findlay 2000). A positive mechanism to strip excessive biofilm growth from the media such as variable rotational speeds, supplemental air, air or water stripping or the ability to reverse shaft rotation must be provided to the RBC units (Tchobanoglous and Burton 1991).

\subsection{Dissolved oxygen levels}

In an aerobic RBC system the biofilm is allowed to form on the medium, which is partly submerged in the wastewater and partly exposed to the air. The rotation alternately exposes this biofilm to atmospheric oxygen and wastewater. Oxygen transfers from the air to the RBC unit in three ways: by oxygen absorption at the liquid film over the biofilm surface when the biofilm is in the air; by direct oxygen transfer at the air-water interface; and by direct oxygen absorption by the microorganisms during the air exposures (Grady 1982).

Usually, as a consequence of an active respiration in the initial stages, the oxygen concentration reaches minimal levels, increasing along the reactor where substrate concentration is low.

An increase in the speed of rotation, at a given level of submergence, leads to an increase in the oxygen transfer capacity of a RBC, in terms of the overall oxygen transfer coefficient, $\mathrm{K}_{\mathrm{L}} \mathrm{a}$ (Rodgers and Zhan 2003). At a particular rotational speed, as submergence increases the $\mathrm{K}_{\mathrm{L}}$ a decreases (Mathure and Patwardhan 2005). Figure 4 shows this behaviour. Some researchers have attempted to develop empirical/mathematical models for the estimation of $\mathrm{K}_{\mathrm{L}} \mathrm{a}$ in $\mathrm{RBC}$ reactors. It is very difficult, however, to model the oxygen transfer because these systems are very complex and include biofilm growth and detachment, the participation of suspended biomass, etc.

Israni et al. (2002) and Mathure and Patwardhan (2005) evaluated the performance of pilot-scale RBC systems in terms of the oxygen transfer efficiency (OTE). They observed that the OTE per unit energy consumed decreased rapidly with an increase in rotational speed and increased with a decrease in hydraulic loading rate. Mathure and Patwardhan (2005) also compared the oxygen transfer efficiencies of a conventional RBC and a RBC with different packings such as rings, superintalox saddles and a wiremesh spiral bundle. The OTE values for the typical RBC were found to be $1-2 \mathrm{~kg} / \mathrm{kWh}$, which were poor in comparison with the values found with packings $(2-5 \mathrm{~kg} / \mathrm{kWh})$.

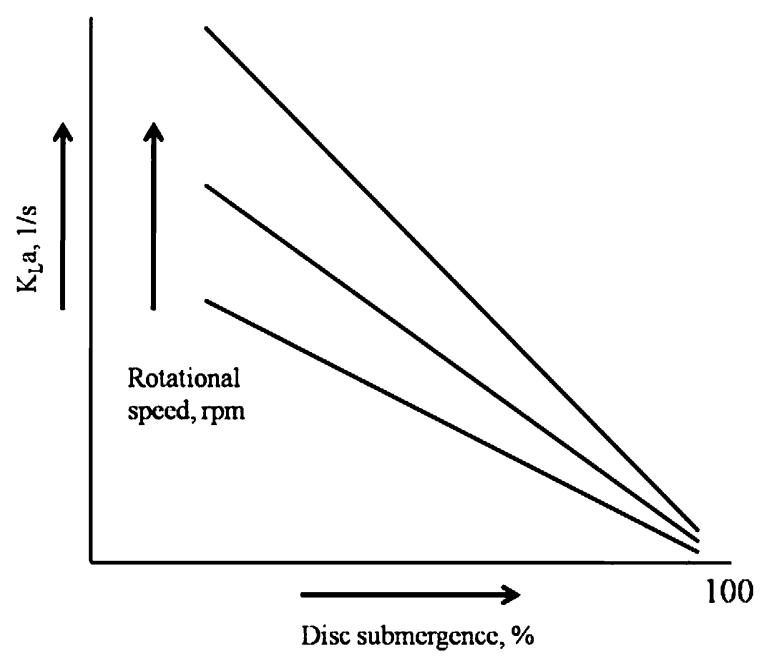

Fig. $4 \mathrm{~K}_{\mathrm{L}} \mathrm{a}$ values versus submergence level and rotational speed of RBC media 
Dissolved oxygen is very important in carbonaceous oxidation and nitrification being the most important design factor for aerobic RBCs. During operation oxygen levels must be properly controlled and to prevent from becoming a limiting factor, initial stages should have at least $2 \mathrm{mg} \mathrm{DO} / \mathrm{l}$ (Nowak 2000). If the rotating motion does not supply sufficient oxygen, a supplemental aeration system should be installed (Surampalli and Bauman 1997; Rodgers and Zhan 2003). Usually this promotes a remarkable performance of the RBC, with an established thinner and active aerobic biomass, allowing considerable cost savings in design and construction of RBC units.

Denitrification occurs if the oxygen in the liquid inside of the RBC media is depleted as well as in the liquid, which surrounds the fixed-film. Primary clarifier effluent is the carbon source for denitrification (Neu 1994).

\subsection{Effluent and solids recirculation}

Effluent or solids recirculation is an attractive solution for existing RBC plants that need to be upgraded to meet stricter effluent limits or for increased performance. Improved $\mathrm{COD}, \mathrm{BOD}_{5}$ and ammonia removal efficiencies have been reported when recirculation is applied, increasing with recirculation ratios (Klees and Silverstein 1992; Neu 1994). Improved nitrification with recirculation has been attributed to the dilution of influent biodegradable organic carbon.

In spite of being optional, recirculation should be considered in the RBC design for adverse conditions. The rate of recirculation recommended is approximately $25 \%$ of the average design flow (Le Groupe Teknika 1988).

\subsection{Step-feeding}

To increase the process capacity, to have a more robust performance and to reduce or prevent overloads, the capability to step-feed RBC stage(s) should be provided. Working in a step-feed mode Janczukowicz and Klimiuk (1992) and Saikaly and Ayoub (2003) improved the removal rates and found higher dissolved oxygen values. The combined effect of step-feed and effluent recirculation in increasing RBC activity was reported by Ayoub and Saikaly (2004), but for a simple soluble substrate.

Besides step-feeding and recirculation other alternative modes of operation can be implemented. For example, to avoid the excessive fungal biofilm growth in the first-stage of the RBC system, after 17 days of operation, Guimarães et al. (2005) reversed the feed inlet. With this simple modification it was possible to double the active biofilm lifetime, improving the removal efficiency.

\subsection{RBC medium submergence}

The percentage of RBC medium submergence depends on several factors, namely the operation type, microorganisms and characteristics of the effluent to be treated. Typically in aerobic processes of municipal wastewater treatment the submergence is about $40 \%$, although in nutrients removal it can attain $60 \%$. However, due to the diversity of industrial wastewater there is no reference value for disc submergence.

Increased submergence was developed to reduce shaft and bearing loads and to improve equipment reliability (Tchobanoglous and Burton 1991). Submerged biological contactors (SBCs), as are called, operate at $70-90 \%$ submergence providing the advantages of larger medium volume available and fewer SBC units required (Schwingle et al. 2005). Submergence in excess of $50 \%$ will decrease the rate of oxygen transfer in the system, thereby if the SBC is used to treat wastewater aerobically, additional air drive units to provide oxygen and rotation must be used (Rodgers and Zhan 2003). The increased submergence combined with the air drive rotation of the SBC has dramatic economic and operating benefits (Schwingle et al. 2005).

The deeper submerged RBCs can also be applied as anaerobic RBCs (Lu and Yeh 1995; Lu et al. 1997a, b) or used for denitrification (Teixeira and Oliveira 2001). In these applications the RBC units are completely closed to avoid air entrance.

At bench-scale various aspects of the anaerobic RBC process have been exploited (Lu and Yeh 1995; Lu et al. 1997a, b). According to Laquidara et al. (1986), this system combines advantages of the aerobic $\mathrm{RBC}$ reactor with the anaerobic process 
(no oxygen transfer limitations, low quantities of waste biological solids and recovery of the usable energy in the form of methane). Due to these advantages, the anaerobic RBC process appears to be well suited for treating both medium-strength and high-strength organic wastewater (Lu et al. 1997a).

There is a great scope of application for anaerobic RBCs in industrial wastewater treatment, which are presently considered suitable for treatment by other anaerobic processes. It is in anaerobic degradation that RBCs could prove to be even more successful than they have been in aerobic treatment (Ware et al. 1990).

The use of deeper submerged RBCs in denitrification is not very widespread. Teixeira and Oliveira (2001) investigated the effect of disc submergence on the performance of lab-scale RBCs, in terms of the denitrification process. For an influent $\mathrm{NO}_{3}^{-}-\mathrm{N}$ concentration of $50 \mathrm{mg} / \mathrm{l}$, at $26^{\circ} \mathrm{C}$ and $2 \mathrm{rpm}$, using citrate as carbon source the higher efficiency $(36.71 \mathrm{~g}$ $\mathrm{NO}_{3}^{-}-\mathrm{N} / \mathrm{m}^{3} \mathrm{~m}^{2}$ removed) was attained with a completely submerged reactor. With the partially $(64.5 \%)$ submerged RBC only $16.97 \mathrm{~g} \mathrm{NO}_{3}^{-}-\mathrm{N} / \mathrm{m}^{3} \mathrm{~m}^{2}$ were removed. Using a pilot-scale $\mathrm{RBC}$ with ethanol as carbon source, at $2 \mathrm{rpm}$ and with a plastic package, Mohseni-Bandpi and Elliott (1996) achieved a maximum nitrate removal rate of $168 \mathrm{mg} \mathrm{NO}--\mathrm{N} / \mathrm{m}^{2} \mathrm{~h}$ for an influent of $130 \mathrm{mg} \mathrm{NO}_{3}^{-}-\mathrm{N} / 1$.

\subsection{RBC scale-up}

Effective design of full-scale RBCs based on data from bench and small pilot-scale studies has proven to be difficult because of the widespread use of an inappropriate scale-up procedure. Scale-up based only on criteria such as equal tip speed, same hydraulic loading, equal number of discs, would alter, for example, the stresses experienced by the microorganisms, as well as the biomass loading and the thicknesses of the biofilm and the liquid film. As a result, the RBC performance is likely to be affected. The influence of various geometries, hydrodynamics and chemical (mass transfer) processes need to be considered in the scale-up of RBCs, and it is not yet clear which of these should drive RBC scale-up (Spengel and Dzombak 1992; Patwardhan 2003).

Design relationships and curves developed by RBC manufacturers and pilot studies and/or full-scale data from similar systems provide the basis to optimize the expansion of an existing RBC system. A mechanistic model is also a useful tool for this purpose. Investigation of the dependence of disc biomass thickness and density on the shear force distribution appears to be the appropriate next step for improving RBC mechanistic models and resolving the RBC scale-up dilemma (Spengel and Dzombak 1992).

\section{Operational problems}

In spite of all of the referred advantages, RBCs have some operating problems such as difficulty in maintenance of an appropriate biofilm thickness under adverse conditions (Sirianuntapiboon 2006). Mechanical failures are also commonly pointed to RBCs. The most common are shaft, bearing and media support structure failures. These may arise due to overloading conditions, excess of biofilm growth, microbiologically influenced corrosion, low frequency corrosion fatigue, improper greasing and inadequate locking of nuts and bolts or poor engineering design (Mba et al. 1999).

A reputation for mechanical failures has restricted the growth of RBC technology (Griffin and Findlay 2000). With a thorough understanding of the mechanisms of mechanical failure and with the development of improved RBC biofilm supports and bearings and stronger shafts, among others, a new approach to RBC design has resulted in units with an expected operational life of 20 years. Also, the improved design could revolutionize applicability of RBCs to high flow/highly populated regions (Mba et al. 1999; Brazil 2006).

\section{RBCs versus other wastewater treatment systems}

RBCs provide a higher level of treatment than conventional high-rate packed-bed reactors. The efficiency of these two systems for the treatment of a UASB reactor effluent was compared by Van Buuren (1991): at an HRT of $3.3 \mathrm{~h}$, the packed-bed reactor removed $50 \%$ of $\mathrm{COD}$ while the $\mathrm{RBC}$ removed $70 \%$. Moreover, at much shorter HRT of $0.24 \mathrm{~h}$ the RBC still achieved 40-80\% COD removal. 
The RBC and activated sludge processes can produce high degrees of treatment. However, RBCs are generally less susceptible to upset due to loading changes and constitute a technology less complicated than activated sludge. Nasr et al. (2007) compared, at laboratory-scale, these two biological processes for the treatment of chemical industrial wastewater $\left(5,239 \mathrm{mg} \mathrm{COD} / 1\right.$ and 2,615 $\left.\mathrm{mg} \mathrm{BOD}_{5} / \mathrm{l}\right)$. As both proved to be effective, producing effluents within the permissible limits, the engineering design of each treatment system (full-scale) was developed and the cost estimate indicated that the construction cost was similar for both systems, while the running cost of activated sludge was almost twice of the RBC. Thus, the use of the RBC system is recommended.

Although it is not possible to find easily comparable values in the literature between RBCs and other biological processes, Table 4 presents the characteristics and performance of several RBCs and of other aerobic biofilm and activated sludge processes.

Estimations reveal that RBCs require only about $25 \%$ of the energy consumption of an activated sludge system (US Filter 1998) and $70-80 \%$ of a packed-bed reactor (Rodgers and Zhan 2003).

Manufacturers of full-scale conventional RBCs specify an energy consumption of $1-1.5 \mathrm{kWh} / \mathrm{kg}$ of $\mathrm{BOD}_{5}$ removed (MSE 2006). Wanner et al. (1990) described an energy usage of $1.6 \mathrm{kWh} / \mathrm{kg}$ of BOD $_{5}$ removed in a full-scale RBC packed with cylindrical PVC offcuts. Watanabe et al. (1994) referred that the electrical power consumption of the pilot RBC was $0.005 \mathrm{kWh} / \mathrm{m}^{2} \mathrm{~d}$ at a rotational speed of $1 \mathrm{rpm}$.

\section{RBC design hints}

Empirical observations form the basis of the design relationships and curves that are usually used to design RBCs for treatment of domestic and some common industrial wastewaters. RBC manufacturers have each developed their own empirical design curves, equations and guidelines based on treatment data collected using their equipment. However, empirical models cannot be relied on to predict the concentration profile of a substrate through an RBC for conditions other than those studied experimentally. In addition, available RBC design curves and equations are not useful for the treatment of leachates or industrial wastewaters that differ in composition from the well-characterized wastewaters for which they were developed. Thus, the relatively slow acceptance and use of RBCs has been attributed, in part, to the lack of a standardized design procedure (Spengel and Dzombak 1992).

In the RBC process design it has to be determined the type and dimensions of medium and degree of submergence, the rotational speed, number of stages, among other parameters, to achieve the optimal degree of treatment. Accordingly, the physical facilities, including the motor, gear system, etc., have to be designed. Moreover, the RBC configuration so established must be such that the overall operation becomes economically viable and attractive (Patwardhan 2003). The process design of a RBC system must also take into consideration the underlying hydrodynamics, biodegradation kinetics, oxygen transfer, development and detachment of the biological film. Thus, the first step in the overall design process should be to carry out laboratory or pilot-scale experiments to determine the biodegradation kinetics over a wide range of operating conditions with the particular wastewater. With this kinetics it is possible to design the large-scale RBC system. A step-wise process design algorithm is presented by Patwardhan (2003).

RBC treatment plants must contain a primary sedimentation tank (for effective removal of grit, debris and grease), the biological chamber and a secondary clarifier. RBC media should be constructed of noncorrosive materials. Disc shafts, bearing and drives should be designed for heavy-duty use. Some RBC design recommendations, like not use highdensity media in the first-stage or prevent that the first-stage keeps an organic surface loading below $30 \mathrm{~g} \mathrm{BOD}_{5} / \mathrm{m}^{2} \mathrm{~d}$, along with many others, were referred along this review and should be respected. Further RBC process recommendations can be found in a design manual produced by WEF and ASCE (WEF and ASCE 1998).

The performance of a RBC will be favoured if it is designed to withstand normal and unusual operation conditions. The use of supplemental aeration, stepfeed or removable baffles (between stages) may increase operational flexibility of RBCs. 


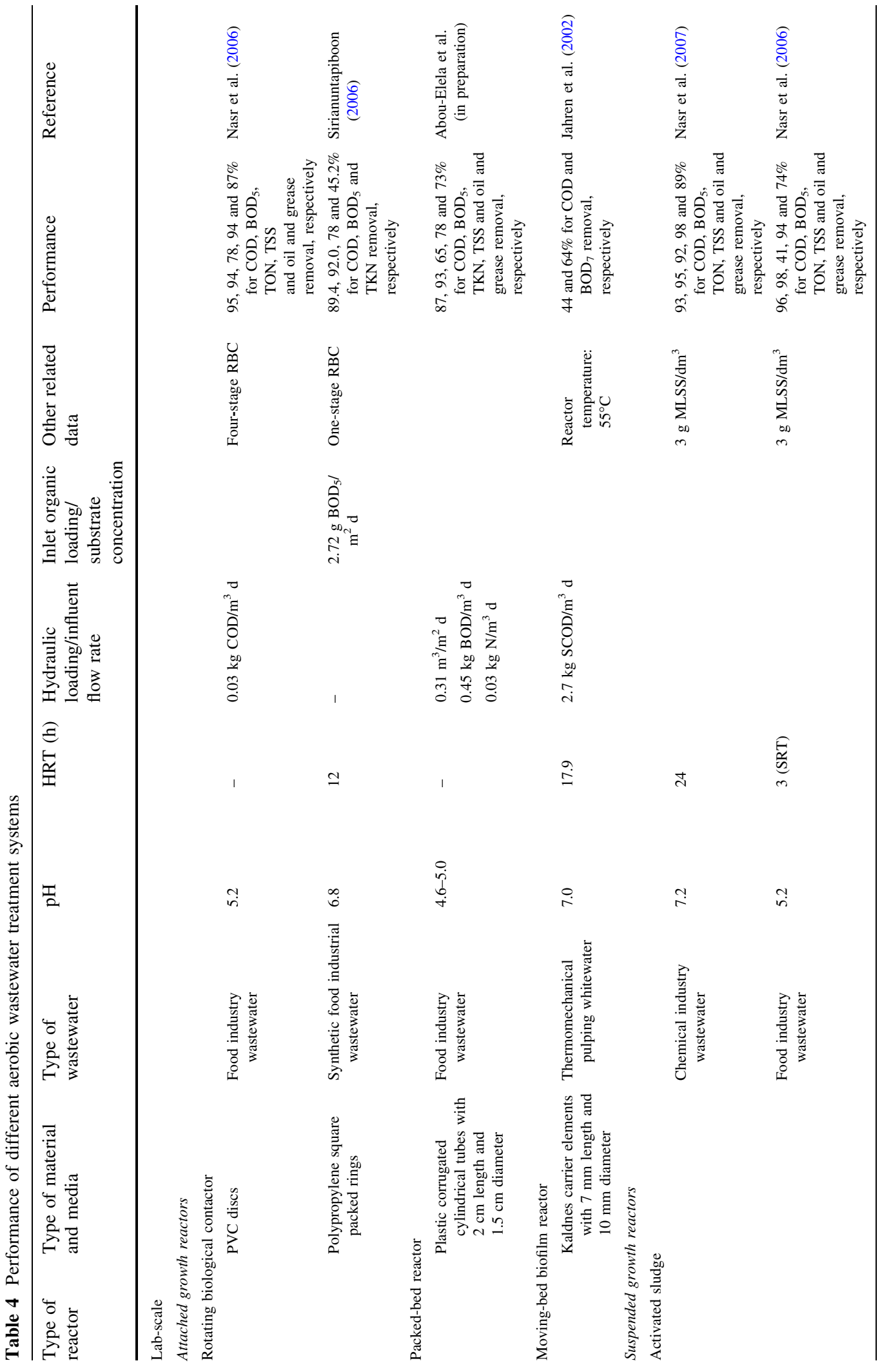




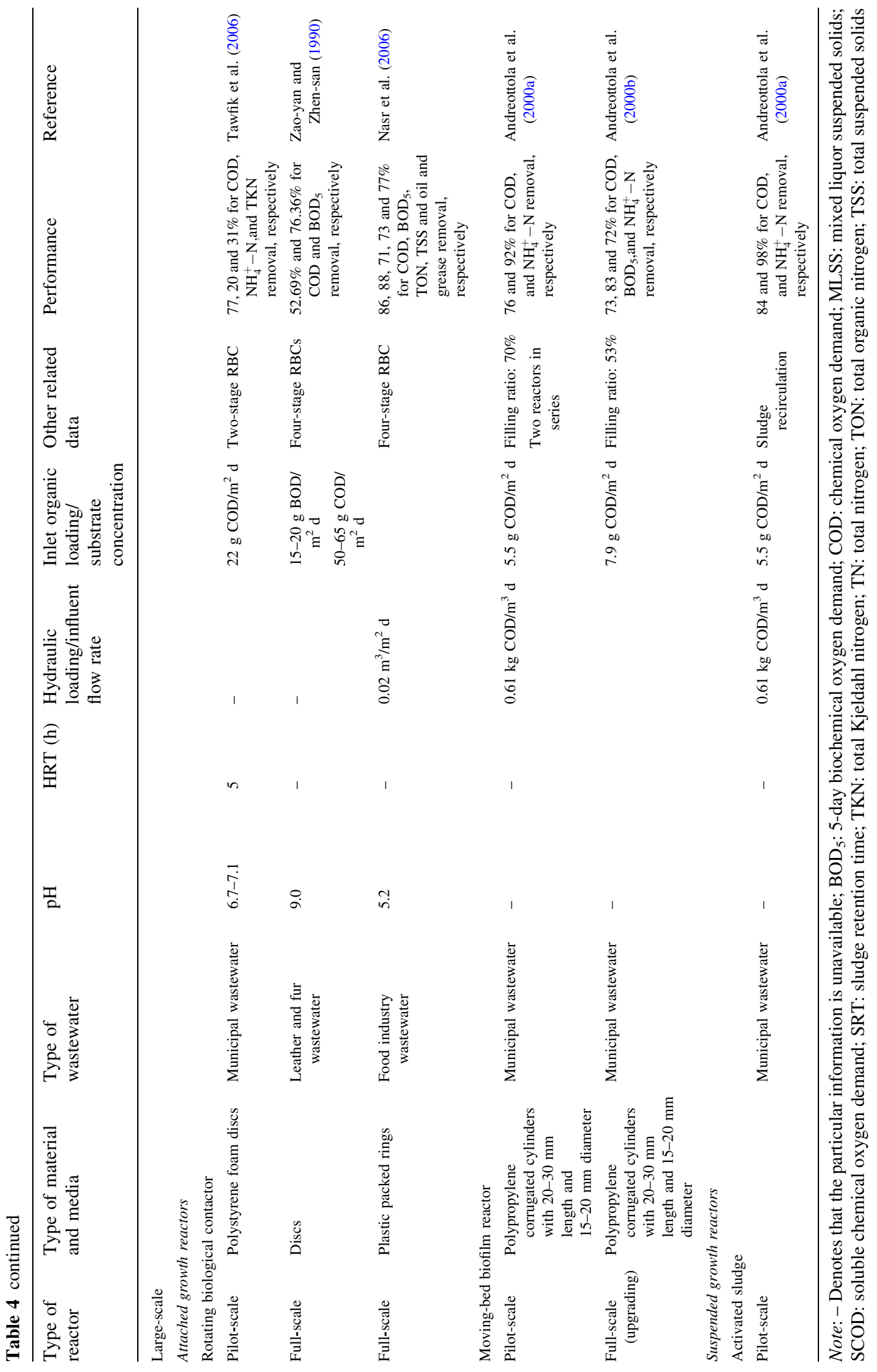




\section{Conclusions}

Rotating biological contactors have been widely used in different treatment applications. However, due to the complex flow patterns where aeration, nutrient and oxygen mass transfer, biofilm growth and detachment, and the participation of suspended biomass must be considered, few mathematical models and with many limitations have been proposed to describe the performance of this type of reactors. Thus, RBCs design is not yet fully mastered and further studies on hydrodynamics, biochemical kinetics and biofilm properties should be carried out.

RBCs have been mainly used in aerobic processes since they provide high OTE. In this field RBC media evolved considerably from the original design of several rotating discs into a unit filled with some lightweight packed supports. As RBCs with packings are relatively recent, there are not many studies on the influence of physical characteristics of the process in these reactors performance. Besides, studies on power consumption, hydrodynamics, mass transfer and biofilm properties also need to be investigated for each type of packing material. Such studies should have an important bearing on scale-up.

More recently, submerged aerobic biological contactors started to be used successfully at full-scale to treat high strength industrial wastewaters, constituting a promising technology. Nevertheless, several improvements can be expected in terms of biofilm supporting media.

Until now few experiments were carried out with anaerobic and anoxic RBCs. Results obtained at laboratory-scale suggest that anaerobic RBCs are effective for the treatment of high-strength organic wastewaters and possible competitors with conventional anaerobic processes. On the other hand, lab-scale studies with anoxic RBCs have been showing high nitrate removal efficiencies. The application of anoxic RBCs, at full-scale, with conventional or packing media, can have an important role in secondary treatment and must be encouraged.

Several modifications can still be expected, specifically concerning recycling and supplemental aeration or step-feeding, in order to improve RBCs performance.

Acknowledgements The authors fully acknowledge the financial support provided by Fundação para a Ciência e Tecnologia (FCT) through grant SFRH/BD/24715/2005.

\section{References}

Abou-Elela SI, Nasr FA, El-Shafai SA Wastewater management in small- and medium-size enterprises: case studies. Environmentalist (in preparation)

Alemzadeh I, Vossoughi M (2001) Biodegradation of toluene by an attached biofilm in a rotating biological contactor. Process Biochem 36:707-711

Andreottola G, Foladori P, Ragazzi M, Tatàno F (2000a) Experimental comparison between MBBR and activated sludge system for the treatment of municipal wastewater. Water Sci Technol 41(4-5):375-382

Andreottola G, Foladori P, Ragazzi M (2000b) Upgrading of a small wastewater treatment plant in a cold climate region using a moving bed biofilm reactor (MBBR) system. Water Sci Technol 41(1):177-185

ATV (1989) Arbeitsblatt A135: Grundsätze für die Bemessung von Tropfkörpern und Tauchkörpern mit Anschlußwerten über 500 Einwohnergleichwerten, 2, Auflage, AbwassertechnischeVereinigung e. V., St Augustin, Germany

Axelsson J, Nilsson U, Terrazas E, Aliaga TA, Welander U (2006) Decolourization of the textile dyes Reactive Red 2 and Reactive Blue 4 using Bjerkandera sp. Strain BOL 13 in a continuous rotating biological contactor reactor. Enzyme Microb Technol 39:32-37

Ayoub GM, Saikaly P (2004) The combined effect of step-feed and recycling on RBC performance. Water Res 38:30093016

Banerjee G (1997a) Hydraulics of bench-scale rotating biological contactor. Water Res 31:2500-2510

Banerjee G (1997b) Treatment of phenolic wastewater in RBC reactor. Water Res 31:705-714

Benefield LD, Randall RW (1980) Biological process design for wastewater treatment. Prentice-Hall Inc., Englewood Cliffs, New Jersey

Brar SK, Gupta SK (2000) Biodegradation of trichloroethylene in a rotating biological contactor. Water Res 34:42074214

Brazil BL (2006) Performance and operation of a rotating biological contactor in a tilapia recirculating aquaculture system. Aquac Eng 34:261-274

Cema G, Wiszniowski J, Zabczyński S, Zablocka-Godlewska E, Raszka A, Surmacz-Górska J (2007) Biological nitrogen removal from landfill leachate by deammonification assisted by heterotrophic denitrification in a rotating biological contactor (RBC). Water Sci Technol 55(8-9): $35-42$

Costley SC, Wallis FM (2000) Effect of flow rate on heavy metal accumulation by rotating biological contactor (RBC) biofilms. J Ind Microbiol Biotechnol 24:244-250

Galvan A, Urbina P, de Castro F (2000) Characterization of filamentous microorganisms in rotating biological contactor biofilms of wastewater treatment plants. Bioprocess Eng 22:257-260

Grady CPL Jr (1982) Modelling of biological fixed films-A state of the art review. In: Wu YC, Smith ED, Miller RD, Patken (eds) Proceedings of the 1st international conference on fixed-film biological processes, April 20-23. University of Pittsburgh, Ohio, USA, pp 344-403 
Grady CPL Jr, Daigger GT, Lim HC (1999) Rotating biological contactor. In: Grady CPL Jr, Daigger GT, Lim HC (eds) Biological wastewater treatment. Marcel Dekker, New York, pp 907-947

Griffin P, Findlay GE (2000) Process and engineering improvements to rotating biological contactor design. Water Sci Technol 41(1):137-144

Guimarães C, Porto P, Oliveira R, Mota M (2005) Continuous decolourization of a sugar refinery wastewater in a modified rotating biological contactor with Phanerochaete chrysosporium immobilized on polyurethane foam disks. Process Biochem 40:535-540

Gupta AB, Gupta SK (2001) Simultaneous carbon and nitrogen removal from high strength domestic wastewater in an aerobic RBC biofilm. Water Res 35:1714-1722

Hanhan O, Orhon D, Krauth Kh, Gunder B (2005) Evaluation of denitrification potential of rotating biological contactors for treatment of municipal wastewater. Water Sci Technol 51(11):131-139

Hoccheimer JN, Wheaton FW (1998) Biological filters: trickling filters and RBC design. In: Libey GS, Timmons MB (eds) Proceedings of the 2nd international conference on recirculation Aquaculture, July 16-19. Roanoke, VA, USA, pp 291-318

Israni SHI, Koli SS, Patwardhan AW, Melo JS, D'souza SF (2002) Phenol degradation in rotational biological contactors. J Chem Technol Biotechnol 77:1050-1057

Jahren SJ, Rintala JA, Ødegaard H (2002) Aerobic moving bed biofilm reactor treating thermomechanical pulping whitewater under thermophilic conditions. Water Res 36:1067-1075

Janczukowicz W, Klimiuk E (1992) The influence of the raw wastes dosing system on technological parameters of the rotating biological disc (RBC) process. Bioresour Technol 42:241-245

Klees R, Silverstein J (1992) Improved biological nitrification using recirculation in rotating biological contactors. Water Sci Technol 26(3-4):545-553

Laquidara MJ, Blanc FC, O’Shaughnessy JC (1986) Development of biofilm, operating characteristics and operational control in the anaerobic rotating biological contactor process. J Water Pollut Control Fed 58:107-114

Le Groupe Teknika (1988) Les disques pour le traitement des eaux usées des petites et moyennes municipalités. Rapport final, Project de développement technologique No. DT87.001

Lu C, Yeh AC (1995) Treatment of high-strength organic wastewaters using an anaerobic rotating biological contactor. Environ Int 21:313-323

Lu C, Li HC, Lee LY (1997a) Effects of disc rotational speed and submergence on the performance of an anaerobic rotating biological contactor. Environ Int 23:253-263

Lu C, Lin MR, Li HC, Lee LY (1997b) Temperature effects on the performance of an anaerobic rotating biological contactor. Environ Technol 18:711-720

Majumder PS, Gupta SK (2007) Removal of chlorophenols in sequential anaerobic-aerobic reactors. Bioresour Technol 98:118-129

Malandra L, Wolfaardt G, Zietsman A, Viljoen-Bloom M (2003) Microbiology of a biological contactor for winery wastewater treatment. Water Res 37:4125-4134
Martín-Cereceda M, Serrano S, Guinea A (2001a) Biofilm communities and operational monitoring of a rotating biological contactor system. Water Air Soil Pollut 126:193-206

Martín-Cereceda M, Alvarez AM, Serrano S, Guinea A (2001b) Confocal and light microscope examination of protozoa and other microorganisms in the biofilms from a rotating biological contactor wastewater treatment plant. Acta Protozool 40:263-272

Mathure P, Patwardhan AW (2005) Comparison of mass transfer efficiency in horizontal rotating packed beds and rotating biological contactors. J Chem Technol Biotechnol 80:413-419

Mba D, Bannister RH, Findlay GE (1999) Mechanical redesign of the rotating biological contactor. Water Res 33:36793688

Mohseni-Bandpi A, Elliott DJ (1996) Nitrate removal from groundwater using an anoxic aerobic rotating biological contactor. Water Sci Technol 34(1-2):323-330

MSE (Métallerie du Sud Est) (2006) Filières d'épuration adaptées aux petites collectivités: les disques biologiques. MSE. Journées Techniques de l'Ascomade, France, http:// www.dklik.planetb.fr/ascomade_demo/upload/ouvrage/ 1145352132.pdf (Visited in December 2007)

Nahid P, Vossoughi M, Alemzadeh I (2001) Treatment of bakers yeast wastewater with a Biopack system. Process Biochem 37:447-451

Najafpour G, Yieng HA, Younesi H, Zinatizadeh A (2005) Effect of organic loading on performance of rotating biological contactors using palm oil mill effluents. Process Biochem 40:2879-2884

Najafpour GD, Zinatizadeh AAL, Lee LK (2006) Performance of a three-stage aerobic RBC reactor in food canning wastewater treatment. Biochem Eng J 30:297-302

Nasr FA, Badr NM, Doma HS (2006) Flavour industry wastewater management case study. Environmentalist 26:31-39

Nasr FA, Doma HS, Abdel-Halim HS, El-Shafai SA (2007) Chemical industry wastewater treatment. Environmentalist 27:275-286

Neu KE (1994) Upgrading of rotating biological contactor (RBC) systems to achieve higher effluent quality, including biological nutrient enrichment and reduction techniques. Water Sci Technol 29(12):197-206

Nowak O (2000) Upgrading of wastewater treatment plants equipped with rotating biological contactors to nitrification and P removal. Water Sci Technol 41(1):145-153

Okabe S, Hiratia K Ozawa Y, Watanabe Y (1996) Spatial microbial distributions of nitrifiers and heterotrophs in mixed-population biofilms. Biotechnol Bioeng 50:24-35

Patwardhan AW (2003) Rotating biological contactors: a review. Ind Eng Chem Res 42:2035-2051

Radwan KH, Ramanujam TK (1997) Studies on organic removal of 2,4-dichlorophenol wastewaters using a modified RBC. Bioprocess Eng 16:219-223

Ramsay J, Shin M, Wong S, Goode C (2006) Amaranth decoloration by Trametes versicolor in a rotating biological contacting reactor. J Ind Microbiol Biotechnol 33: 791-795

Rodgers M, Zhan XM (2003) Moving-medium biofilm reactors. Rev Environ Sci Biotechnol 2:213-224 
Saikaly P, Ayoub GM (2003) Ammonia nitrogen removal in step-feed rotating biological contactors. Water Air Soil Pollut 150:177-191

Salvadó H, Palomo A, Mas M, Puigagut J, Gracia MP (2004) Dynamics of nematodes in a high organic loading rotating biological contactors. Water Res 38:2571-2578

Schwingle TA, Lepak AJ, Wenta RJ (2005) Refining applications. Hydrocarbon Engineering. January

Selvam K, Swaminathan K, Song MH, Chae K-S (2002) Biological treatment of a pulp and paper industry effluent by Fomes lividus and Trametes versicolor. World J Microbiol Biotechnol 18:523-526

Sirianuntapiboon S (2006) Treatment of wastewater containing $\mathrm{Cl}_{2}$ residue by packed cage rotating biological contactor (RBC) system. Bioresour Technol 97:1735-1744

Sirianuntapiboon S, Chuamkaew C (2007) Packed cage rotating biological contactor system for treatment of cyanide wastewater. Bioresour Technol 98:266-272

Spengel DB, Dzombak DA (1992) Biokinetic modeling and scale-up considerations for rotating biological contactors. Water Environ Res 64:223-234

Surampalli RY, Baumann ER (1997) Role of supplemental aeration in improving overloaded first-stage RBC performance. Water Air Soil Pollut 98:1-15

Tawfik A, Klapwijk B, el-Gohary F, Lettinga G (2002) Treatment of anaerobically pre-treated domestic sewage by a rotating biological contactor. Water Res 36:147-155

Tawfik A, Temmink H, Zeeman G, Klapwijk B (2006) Sewage treatment in a rotating biological contactor (RBC) system. Water Air Soil Pollut 175:275-289

Tchobanoglous G, Burton FL (1991) Wastewater engineering: treatment, disposal and reuse. Metcalf \& Eddy, 3rd ed. McGraw-Hill International Editions, New York

Teixeira P, Oliveira R (2001) Denitrification in a closed rotating biological contactor: effect of disk submergence. Process Biochem 37:345-349
Torkian A, Hashemian SJ, Alinejad K (2003) Posttreatment of upflow anaerobic sludge blanket-treated industrial wastewater by a rotating biological contactor. Water Environ Res 75:232-237

US Filter (1998) Applying the rotating biological contactor process. US Filter. Bulletin No. USF 315-13A6, http:// www.waow.net/Brochures/RBC.pdf (Visited in December 2007)

Van Buuren (1991) Post-treatment methods for effluent of UASB reactors treating domestic sewage. Internal report No. 91-3. Wageningen University, Department of Environmental Technology, The Netherlands

Wanner J, Sýkora M, Kos M, Miklenda J, Grau P (1990) Packed-cage RBC with combined cultivation of suspended and fixed-film biomass. Water Sci Technol 22(12):101-111

Ware AJ, Pescod MB, Storch B (1990) Evaluation of alternatives to conventional disc support media for rotating biological contactors. Water Sci Technol 22(1-2): 113-117

Watanabe Y, Bang DY, Itoh K, Matsui K (1994) Nitrogen removal from wastewaters by a bio-reactor with partially and fully submerged rotating biofilms. Water Sci Technol 29(10-11):431-438

WEF (Water Environment Federation) \& ASCE (American Society of Civil Engineers) (1998) Design of municipal wastewater treatment plants, WEF Manual of practice No. 8, ASCE Manual and report on engineering practice No. 76. Alexandria and Reston, USA

Zao-yan Y, Zhen-san F (1990) Treatment of leather and fur wastewater by a rotating biological contactor. Water Sci Technol 22(1-2):119-126 